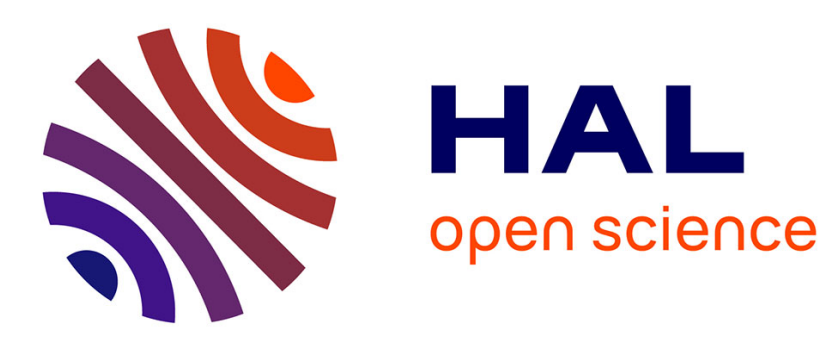

\title{
Elastomer monolayers adsorbed on mica surfaces by nitroxide-mediated polymerisation
}

L. Ghannam, M. Bacou, H. Garay, M.E.R. Shanahan, Jeanne François, Laurent Billon

\section{- To cite this version:}

L. Ghannam, M. Bacou, H. Garay, M.E.R. Shanahan, Jeanne François, et al.. Elastomer monolayers adsorbed on mica surfaces by nitroxide-mediated polymerisation. Polymer, 2004, 45 (21), pp.70357045. 10.1016/j.polymer.2004.08.002 . hal-01582055

\section{HAL Id: hal-01582055 https://hal.science/hal-01582055}

Submitted on 1 Jun 2021

HAL is a multi-disciplinary open access archive for the deposit and dissemination of scientific research documents, whether they are published or not. The documents may come from teaching and research institutions in France or abroad, or from public or private research centers.
L'archive ouverte pluridisciplinaire HAL, est destinée au dépôt et à la diffusion de documents scientifiques de niveau recherche, publiés ou non, émanant des établissements d'enseignement et de recherche français ou étrangers, des laboratoires publics ou privés. 


\title{
Elastomer monolayers adsorbed on mica surfaces by nitroxide-mediated polymerisation
}

\author{
Leïla Ghannam ${ }^{\mathrm{a}, \mathrm{b}}$, Marie Bacou ${ }^{\mathrm{a}}$, Hélène Garay ${ }^{\mathrm{a}}$, Martin E.R. Shanahan ${ }^{\mathrm{a}}$, \\ Jeanne François ${ }^{\mathrm{b}}$, Laurent Billon ${ }^{\mathrm{b}, *}$ \\ ${ }^{a}$ Centre de Matériaux de Grande Diffusion, Ecole de Mines d'Alès-Pau Cedex, France \\ ${ }^{\mathrm{b}}$ Laboratoire de Physico-Chimie des Polymères, UMR CNRS 5067, Hélioparc Pau-Pyrénées, 2 avenue Pierre Angot, 64053 Pau Cedex 9, France
}

\begin{abstract}
We reported the first synthesis of Poly( $n$-butyl acrylate) by in situ nitroxide-mediated polymerisation from the surface of mica while preserving its lamellar structure. To obtain this polymer adsorbed to mica surface, a free radical initiator $2,2^{\prime}$-azobis(isobutyramidine hydrochloride) (AIBA) was attached by ion exchange to the surface of mica, and the resulting was used as a initiator to polymerise butyl acrylate. The kinetic studies show that the initiator adsorbed to mica surface successfully initiated the radical polymerisation of butyl acrylate. Adsorbed polymer was indeed obtained, in different amounts depending on reaction time, the XRD patterns of resulting products indicate that the polymer chains did not intercalate the aluminosilicate layers, as expected.
\end{abstract}

Keywords: Polymer mono-layer; Inorganic/organic material; Mica

\section{Introduction}

Grafting of polymers to inorganic surfaces is of potential interest in a wide variety of fields such as composite materials and adhesives, chromatography, protein immobilisation, colloid stabilisation, medicine, dentistry and cosmetics. A number of theoretical and experimental studies have dealt with polymer chains terminally grafted to inorganic surfaces [1]. While in some cases the macromolecules are surmised to be attached to the surface via covalent bonds, in other studies the chains are adsorbed in a more or less reversible way according to the equilibrium with the bulk.

Among the various silicates (montmorillonite, silica, talc, mica, etc.), mica is frequently used as a filler in polymeric materials. For example, mica 'paper' confers excellent electrical properties to polymer composites for high-voltage insulators [2], mica 'powders' are used as fillers to increase the stiffness of thermoplastic polymers, especially polypropylene [3], and mica 'platelets' show

\footnotetext{
* Corresponding author. Tel.: +33-559407609; fax: +33-559407623.

E-mail address: laurent.billon@univ-pau.fr (L. Billon).
}

promise for permeation barriers in polymer composites [4]. In order to get more information about the roles of these charges in a polymer matrix, it is very important to characterise the polymer/filler interactions and establish the dimensions of the macromolecular chains grafted or adsorbed on the surface.

Over the last 10 years, important progress has been made in the control of free radical polymerisation (CRP) and in the understanding of the mechanisms involved. Three main methods with their specificities and limitations have been shown to allow a controlled propagation of the free radicals: nitroxide-mediated radical polymerisation (NMP) [5,6], atom transfer radical polymerisation (ATRP) [7-9], and reversible addition-fragmentation chain transfer (RAFT) $[10,11]$ can be used to prepare well defined polymeric samples starting from various monomers.

NMP attracts much interest because it is based on potentially simpler systems than ATRP or RAFT and does not require additional of sensitive metal-based products. Since the use of 2,2,6,6-tetramethyl-1-piperininyloxy (TEMPO) by Georges et al. [5] to control the polymerisation of styrene, many other studies have been made to improve NMP by using 
various nitroxides. Gnanou et al. [12,13], showed that the nitroxide $N$-tert-butyl- $N$-[1-diethylphosphono-(2,2-dimethylpropyl) nitroxide] (DEPN), developed by Tordo and called SG1 (ATOFINA), is efficient enough to control the radical polymerisation of styrene and alkyl acrylates. This method leads to polystyrene (PS) and poly ( $n$-butylacrylate) $(\mathrm{P}(n$-BA) with a polydispersity lower than 1.3 , and allows faster propagation than any other nitroxides.

The efficiency of NMP coupled with a grafting technique has been demonstrated in our laboratory $[14,15,23]$, and more recently by Beyou et al. [16], using silica particles or silicon wafer. In these cases two different approaches can be used, based on a unimolecular system called alkoxyamine [15-17], and on a bimolecular system based on a azoïc [14, $15,23]$, or a peroxide [18] with a stable free radical. In each case, it has been demonstrated that the living/controlled character of the polymerisation can occur directly from the surface in the presence of nitroxide.

The general theme of the research reported here concerns the preparation of hybrid inorganic/organic materials, starting from a layered mineral covered by an acrylic polymer layer in order to generate new optical properties. Mica was chosen for this study. Mica is a chemically inert alumino-silicate mineral. Its crystal structure consists of preliminary negatively charged 2:1 layers whose charges are compensated by interlayer cations (monovalent $\left(\mathrm{Na}^{+}\right.$, $\mathrm{K}^{+}$, etc.) or divalent $\left(\mathrm{Ca}^{2+}, \mathrm{Mg}^{2+}\right.$, etc.) [19]. Each 2:1 layer is constituted by two tetrahedral sheets sandwiching one octahedral sheet. It was very important to control the nature and the thickness of the polymer layer, and so a low $T_{\mathrm{g}}$ polymer has been considered, poly ( $n$-butyl acrylate) $\mathrm{P}(n$ BA). In this paper, for the first time we describe the method used to control polymerisation of butyl acrylate at the surface of mica, while preserving its lamellar structure, by using the NMP process. The preparation of hybrid mica/ PBA material requires a first step of adsorption of an initiator (here 2,2' -azobis (iso-butyramidine hydrochloride) (AIBA) and a second step of polymerisation, (Scheme 1).

\section{Experimental section}

\subsection{Materials}

The soft mica ${ }^{\circledR}$ samples were received from Comptoire Minérale des Matériaux Primaires CMMP (France). The
Table 1

Physico-chemical characteristics of the mica used

\begin{tabular}{ll}
\hline Chemical analysis (\%) & \\
\hline $\mathrm{SiO}_{2}$ & $49.2 \%$ \\
$\mathrm{Al}_{2} \mathrm{O}_{3}$ & $28.3 \%$ \\
$\mathrm{~K}_{2} \mathrm{O}$ & $9.8 \%$ \\
$\mathrm{Fe}_{2} \mathrm{O}_{3}$ & $6.9 \%$ \\
$\mathrm{Na}_{2} \mathrm{O}$ & $0.8 \%$ \\
$\mathrm{CaO}$ & $1 \%$ \\
$\mathrm{H}_{2} \mathrm{O}$ & $0.2 \%$ \\
$\mathrm{Physical}$ properties & \\
Specific gravity $\left(\mathrm{g} / \mathrm{cm}^{3}\right)$ & 2.80 \\
pH (in water) & 9 \\
Average particle size $(\mu m)$ & $45-150$ \\
Specific surface (molecules $\left./ \mathrm{nm}^{2}\right)$ & 5.9 \\
\hline
\end{tabular}

physico-chemical characteristics of this mica are given in Table 1.

The initiator used was a water-soluble bicationic azo compound previously reported for the preparation of polymer-clay composites [20], 2,2'-azobis (iso-butyramidine hydrochloride) (AIBA), (Scheme 2).

The counter-radical SG1 (90\%) was received from ATOFINA, (Scheme 3).

The monomer $n$-butyl acrylate (n-BA) (Aldrich) and solvents mentioned in the present paper were used as received.

\subsection{Adsorption of AIBA on mica}

To connect the initiator to mica, we set the following conditions.

1. It possesses a cationic group that can interact with the negatively charged silicate layer;

2. It should be able to decomposed at the polymerisation temperature of $n$-BA $\left(120^{\circ} \mathrm{C}\right)$.

To satisfy this condition the AIBA initiator was chosen because it becomes positively charged in solution and is able to adsorb onto a negative surface, (Scheme 4).

The mica powders were dispersed in ethanol solutions of the initiator at ambient temperature. The resulting suspensions were magnetically stirred overnight. After filtration, the solids were washed with ethanol, filtered again, and

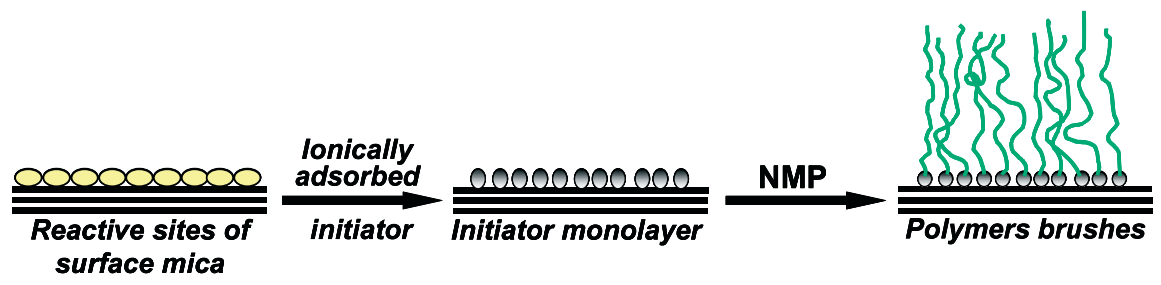

Scheme 1. Schematic representation of the concept for the preparation of polymer brushes using ionically adsorbed initiators for controlled free radical-chain polymerisation. 
<smiles></smiles>

Scheme 2. Structure of AIBA.

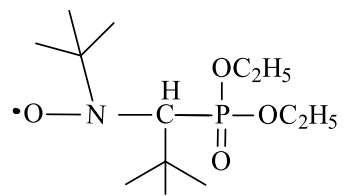

Scheme 3. Structure of SG1.

dried by lyophilisation for $24 \mathrm{~h}$. The amount of adsorbed initiator was determined by thermal gravimetric analysis (TGA).

\subsection{Polymerisation}

Mica powder $(100 \mathrm{mg})$ with cationic initiator adsorbed on the surface were dispersed in a mixture of butyl acrylate monomer $(n$-BA) $([$ Acrylate] $/ 2[\mathrm{AIBA}]=500)$ and SG1 (slight excess $([\mathrm{AIBA}] /[\mathrm{SG} 1]=0.05)$ ). This mixture was thoroughly degassed with nitrogen and heated at $120{ }^{\circ} \mathrm{C}$ for $4,14,24$ and $48 \mathrm{~h}$. The next stage was centrifugation of the mixture in acetone for $60 \mathrm{~min}$ at $5000 \mathrm{rpm}$. After decantation, the solid was recovered and dried at ambient temperature for several hours, and the supernatant was precipitated in a large volume of ethanol/water (1/0.05) in order to determine the molecular weight of desorbed polymer chains.

\subsection{Characterisation}

${ }^{1} \mathrm{H}$ NMR and proton decoupled ${ }^{13} \mathrm{C}$ NMR spectra were recorded at $400 \mathrm{MHz}$ on a Bruker Advanced AM400 spectrometer in $\mathrm{CDCl}_{3}$ and the chemical shifts $(\delta)$ in ppm were referred to internal trimethylsilane (TMS). MagneticAngle Spinning ${ }^{13} \mathrm{C}$ NMR was also employed.

Fourier Transform Infrared (FTIR) spectra were recorded using a Burker IFS 66/S spectrometer at a resolution of $4 \mathrm{~cm}^{-1}$ in absorption mode, $100-1000$ scans were accumulated.

Thermal gravimetric analysis (TGA) was carried out using a System TA 2950 apparatus, to determine the amount of bound polymer chains adsorbed to mica surfaces in a temperature range $50-600{ }^{\circ} \mathrm{C}$ at a scan rate of $10{ }^{\circ} \mathrm{C} / \mathrm{min}$ in air.

The molecular weights of the polymer and the polydispersity were determined by size exclusion chromatography (SEC), using a 2690 Waters System with THF as the mobile phase. Molecular weights were calculated relative to polystyrene standards.

X-ray photoelectron spectroscopy (XPS) analysis were performed with a Surface Science Instrument (SSI) spectrometer at room temperature, using monochromatic and focused (spot diameter of $600 \mu \mathrm{m}, 100 \mathrm{~W}$ ) $\mathrm{Al} \mathrm{K}$ radiation $(1486 \mathrm{eV})$ under a residual pressure of $5 \times 10^{-8} \mathrm{~Pa}$. The hemispherical analyser worked in constant pass energy mode, $50 \mathrm{eV}$ for high resolution spectra. The binding energy scale was calibrated from the carbon contamination using the $\mathrm{C}_{1 \mathrm{~s}}$ line $(284.6 \mathrm{eV}$ ) (a mean atomic percentage of $8 \%$ was determined).

The X-ray diffraction (XRD) data from powder samples were recorded using reflection geometry with pseudofocusing known as Bragg-Brentano. They were collected at room temperature on a INEL CPS 120 powder diffractometer (calibrated with NAC $\left(\mathrm{Na}_{2} \mathrm{Ca}_{3} \mathrm{Al}_{2} \mathrm{~F}_{14}\right)$ ) with monochromatized $\mathrm{Cu} \mathrm{K} \mathrm{K}_{\alpha}\left(\lambda_{\text {measure }}=0.15406 \mathrm{~nm}\right)$ radiation $(30-40 \mathrm{kV})$.

\section{Results and discussion}

\subsection{Adsorption of AIBA on mica}

After adsorption of the initiator on mica, the resulting surface was first analysed qualitatively by NMR and FTIR spectroscopy.

A solid-state ${ }^{13} \mathrm{C}$ NMR CP/MAS spectrum of mica with adsorbed AIBA was obtained with clear signals characteristic of AIBA at $178.28 \mathrm{ppm}\left(\mathrm{C}_{\alpha}\right)$ (carbon atoms of amidinium $(\mathrm{C}=\mathrm{N})$ ), $73.92 \mathrm{ppm}\left(\mathrm{C}_{\beta}\right)$ (carbon atoms of $\left.\mathrm{C}-\mathrm{N}\right)$, 28.32 and $25.82 \mathrm{ppm}\left(\mathrm{C}_{\gamma}\right)$ (carbon atoms of $\mathrm{CH}_{3}$ ), confirming the presence of the azoïc compound on the mica surface, (Fig. 1).

Fig. 2 reproduces the FTIR spectra of pure soft mica ${ }^{\circledR}$, which exhibit no notable peak, and that of AIBA which is characterised in this wavenumber range by the $\mathrm{C}=\mathrm{N}$ and $\mathrm{NH}$ vibrations at 1681 and $1625 \mathrm{~cm}^{-1}$, respectively. The presence in the spectrum of the surface modified mica of

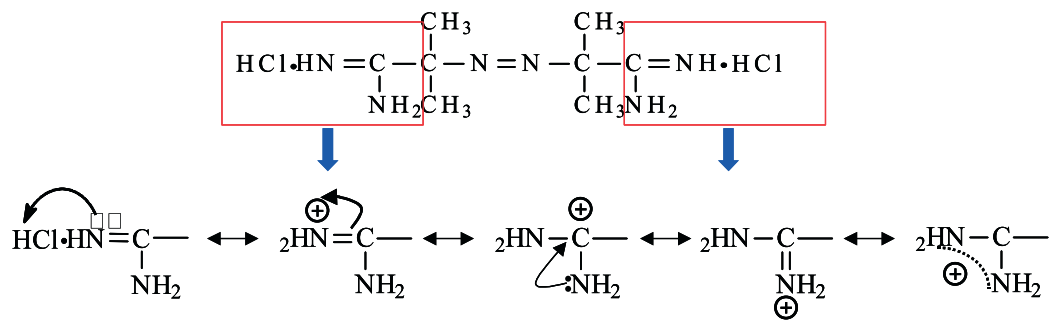

Scheme 4. Mechanism of AIBA in solution. 


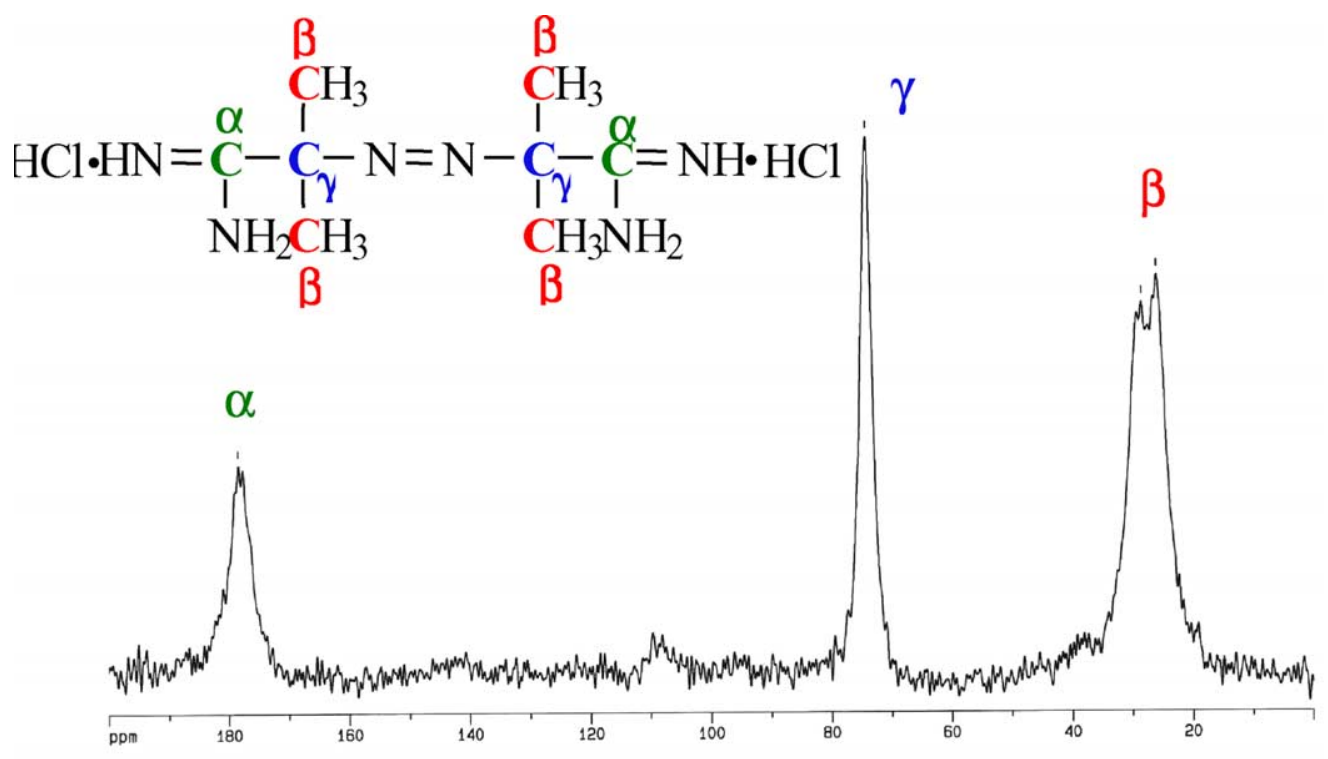

Fig. $1 .{ }^{13} \mathrm{C}$ CP/MAS solid-state NMR spectrum of AIBA adsorbed-mica.

adsorption at these two wavenumbers confirms adsorption of AIBA on the mica surface. Moreover, the spectrum of the modified material displays peaks at 2730 and $2940 \mathrm{~cm}^{-1}$ corresponding to the stretching vibrations $(\mathrm{C}-\mathrm{H})$ characteristic of adsorbed AIBA.

These qualitative analysis show that the initiator is well adsorbed on the mica, but further analysis is necessary to determine the quantity of AIBA adsorbed. This was effected by TGA, (Fig. 3). Considering that mica does not degrade below $1000{ }^{\circ} \mathrm{C}$, only the organic matter (initiator), present at the surface of the inorganic substrate, degrades totally at temperatures lower than $700{ }^{\circ} \mathrm{C}$. After comparison of the thermograms of mica with adsorbed AIBA (Fig. 3b), with that of soft mica ${ }^{\circledR}$ (Fig. 3a), it was concluded that $0.4 \mathrm{mg}$ of

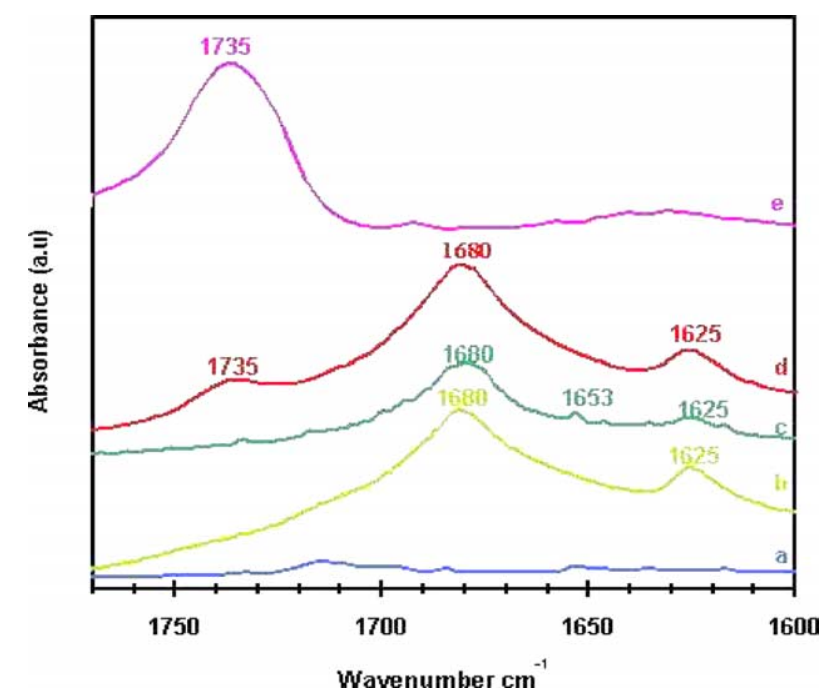

Fig. 2. FTIR spectra of (a) mica soft, (b) pure AIBA, (c) AIBA adsorbedmica, (d) poly ( $n$-BA) (4 h) coated-mica, and (e) Poly ( $n$-BA) (48 h) coatedmica.
AIBA per $1 \mathrm{mg}$ of mica $(1.5 \mu \mathrm{mol} / \mathrm{mg}$ of mica $)$ was adsorbed to mica surface.

\subsection{Polymerisation}

Mica with adsorbed AIBA $(0.4 \mathrm{mg}$ per $1 \mathrm{mg}$ of mica) was treated with $n$-BA at $120^{\circ} \mathrm{C}$. After four periods $4,14,24$ and $48 \mathrm{~h}$, the reaction was stopped and the products were analysed. As the initiator is bound to the surface by one or both ends, it is possible, in the first case, that the second end of the initiator can diffuse into solution and start a polymerisation reaction there. Not all polymer which had formed is ionically adsorbed to the mica surface. Two types of polybutylacrylate $\mathrm{P}(n-\mathrm{BA})$ were found: polymer 'bound' to the mica (not removed from the mica surface by acetone extraction) and $\mathrm{P}(n-\mathrm{BA})$ precipitated in ethanol/ $\mathrm{H}_{2} \mathrm{O}$. If the radical was adsorbed by one ionic end, the $\mathrm{P}(n-\mathrm{BA})$ attached to the surface cannot be removed by extraction with good organic solvents of this polymer such as acetone or tetrahydrofuran.

\subsection{Characterisation of the free chains}

\subsubsection{Size exclusion chromatography (SEC)}

The NMP techniques allow the preparation of polymers with narrow molecular weight distribution and precise control of chemical composition and polymer architecture. The basic underlying mechanism is a reversible capping of the free radical end of the growing polymer chains. The counter radical chosen SG1 works very well for acrylates and is very tolerant to functional groups in the monomers, $[12,13,21]$. The low concentration of active chain ends suppresses detrimental side reactions such as radical coupling. In the ideal case, this leads to a 'living' polymer with a narrow molecular weight distribution, and makes it 

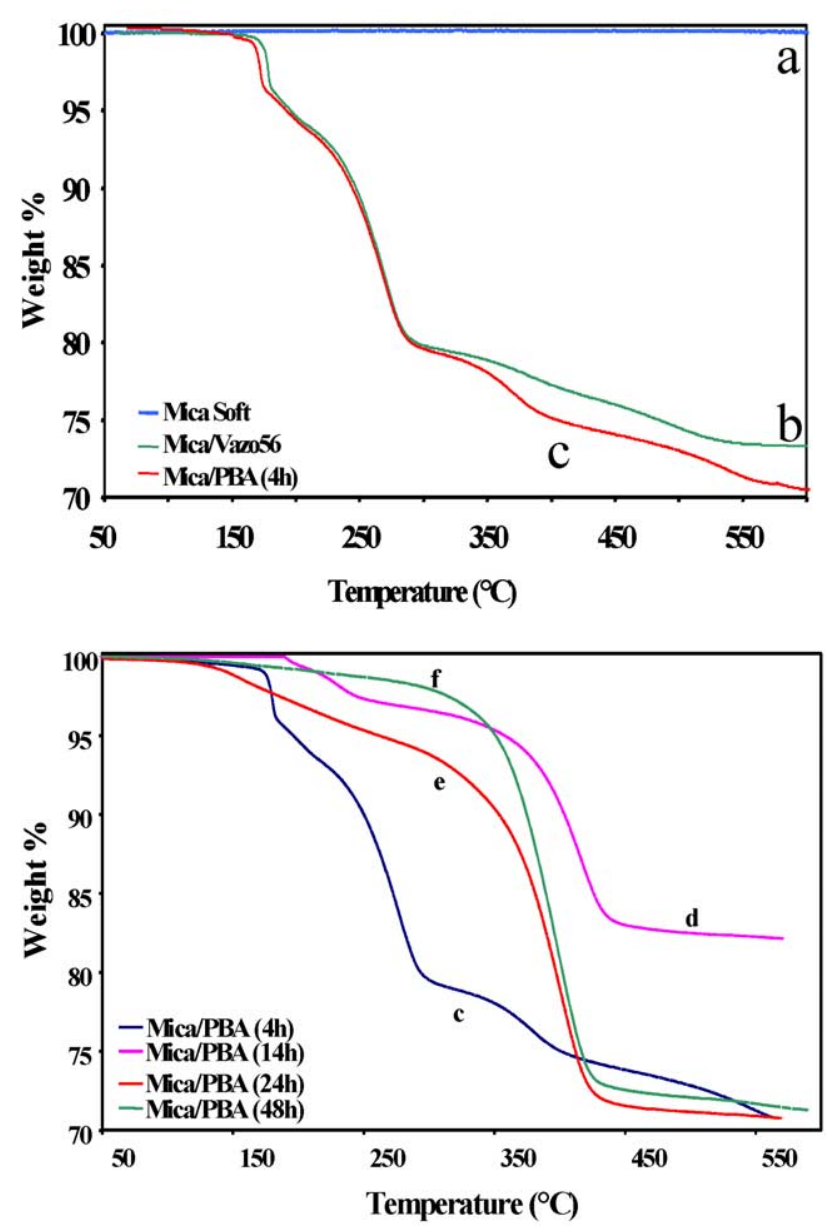

Fig. 3. Weight loss (\%) versus temperature for (a) soft mica, (b) AIBA adsorbed-mica, (c) poly ( $n$-BA) $(4 \mathrm{~h})$ coated-mica, and (d) poly $(n-\mathrm{BA})$ $(24 \mathrm{~h})$ coated-mica, and (e) poly $(n-\mathrm{BA})(48 \mathrm{~h})$ coated-mica.

possible to prepare block copolymers. Table 2 gives the number and weight average molecular weights, $\bar{M}_{\mathrm{n}}$ and $\bar{M}_{\mathrm{w}}$, of the free $\mathrm{P}(n-\mathrm{BA})$ polymer, determined by GPC, as function of the reaction time.

Both $\bar{M}_{\mathrm{n}}$ and $\bar{M}_{\mathrm{w}}$ are relatively low at low reaction times with a very good polydispersity index (1.15), while they increase with reaction time. It must be noted that the polydispersity which remains rather low for $t=24 \mathrm{~h}(1.3)$ strongly increases when $t=48 \mathrm{~h} \mathrm{(2.1).}$

The chromatogrammes of the four samples reported in Fig. 4 confirm the high molecular weights of unbound polymers at 24 and $48 \mathrm{~h}$. This polydispersity at high conversion rate is due to the decomposition of the nitroxide $\mathrm{SG} 1$ at the reaction temperature $120^{\circ} \mathrm{C}[12,13]$.

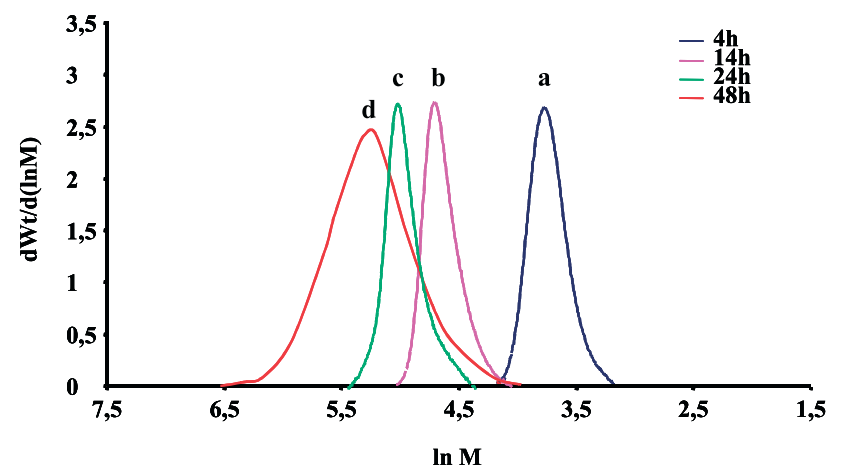

Fig. 4. $\mathrm{d} W t / \mathrm{d}(\ln (M))$ versus $\ln (M)$ for unbounded polymer at (a) $4 \mathrm{~h}$, (b) $14 \mathrm{~h}$, (c) $24 \mathrm{~h}$ and (d) $48 \mathrm{~h}$ of polymerisation.

3.3.1.1. Kinetics studies. For the nitroxide mediated polymerisation of $n$-BA initiated by AIBA, the kinetic studies in the absence and the presence of mica would give all the criteria of 'livingness' in the presence of SG1. The results of Tables 2 and 3 show that the molecular weight increases with conversion, and the polydispersity remains in both cases low $\left(M_{\mathrm{w}} / M_{\mathrm{n}}<1.2\right)$ for $24 \mathrm{~h}$, becoming high for $48 \mathrm{~h}\left(M_{\mathrm{w}} / M_{\mathrm{n}}=2\right)$. It may also be noted that, for an identical reaction time, these molecular weights are higher in the absence of the mineral filler (mica). These results show that the presence of mica in the bulk reduces the speed of polymerisation in consequence of less low molecular weights. On the other hand, the presence of the mineral does not have an influence on the index of polydispersity.

The comparison of molecular weights in Tables 2 and 3 shows an important difference between the values obtained experimentally and theoretically. This could be attributed to the efficiency of the initiator and demonstrates that only a part of the initiator was reacted, leading to the presence of residual initiator or organic fragment of the initiator on the mica surface (see Section 3.4).

One of the features of NMP is that the number of active species remains almost constant throughout the reaction. This may be demonstrated by using the classical representation of the NMP process, i.e. the plot of $\ln [M]_{0} /[M]$ as a function of time, $[\mathrm{M}]_{0}$ and $[\mathrm{M}]$, respectively standing for the original and current monomer concentration (by their proportionality with the weight of formed polymer). As shown in Fig. 5a, the plots are a straight line, indicating that the number of propagating species $\left(\mathrm{kp}\left[\mathrm{P}^{*}\right]\right)$ remained approximately constant in this range time and confirming the control of polymerisation in presence and absence of mica.

The limitation of the number of transfer reactions is

Table 2

Molecular weights of unbound Poly $(n-\mathrm{BA})$ (with mica)

\begin{tabular}{lccccc}
\hline Time of reaction $(\mathrm{h})$ & $\mathrm{C}(\%)$ & $M_{\mathrm{n}, \mathrm{th}}(\mathrm{g} / \mathrm{mol})$ & $M_{\mathrm{n}}(\mathrm{g} / \mathrm{mol})$ & $M_{\mathrm{w}}(\mathrm{g} / \mathrm{mol})$ & $M_{\mathrm{w}} / M_{\mathrm{n}}$ \\
\hline 4 & 2.9 & 1900 & 5700 & 6600 & 1.14 \\
14 & 33 & 21,000 & 30,000 & 34,200 & 1.14 \\
24 & 58 & 37,000 & 74,000 & 86,600 & 1.17 \\
48 & 83 & 53,000 & 119,000 & 260,000 & 2.1 \\
\hline
\end{tabular}


Table 3

Summary of results of kinetic studies for free polymers (without mica)

\begin{tabular}{lccc}
\hline Time of reaction $(\mathrm{h})$ & $\mathrm{C}(\%)$ & $M_{\mathrm{n}, \mathrm{th}}^{\mathrm{a}}(\mathrm{g} / \mathrm{mol})$ & $M_{\mathrm{n}, \exp }(\mathrm{g} / \mathrm{mol})$ \\
\hline 2 & 1.1 & 700 & 2000 \\
4 & 2.4 & 1500 & 4500 \\
6 & 9.1 & 5800 & 9500 \\
14 & 33 & 21,000 & 40,000 \\
24 & 66 & 42,000 & 1.10 \\
48 & 88 & 56,000 & 1.14 \\
\hline
\end{tabular}

${ }^{\mathrm{a}} \mathrm{M}_{\mathrm{n}, \mathrm{th}}=([$ Monomer]/2[Initiator] $) \times$ Monomer molecular weight $\times$ Conversion.

another consideration used to ascertain the controlled character of the reaction. This could be checked by plotting the molecular weight of the obtained polymer versus conversion. Fig. 5b demonstrates that this system shows an living behaviour and makes it very suitable for the synthesis of acrylic block copolymers.

If poly(butyl acrylate) were grafted from the surface via surface initiated polymerisation, first order kinetics would be expected [22,23]. Fig. 5b shows this type of kinetics by the linearity of the plot of molecular weight of polymer obtained in presence of mica versus conversion. When pure mica was used in place of AIBA-adsorbed mica in polymerisation medium, the amount of soluble polymer formed was similar, but no bound polymer was produced.
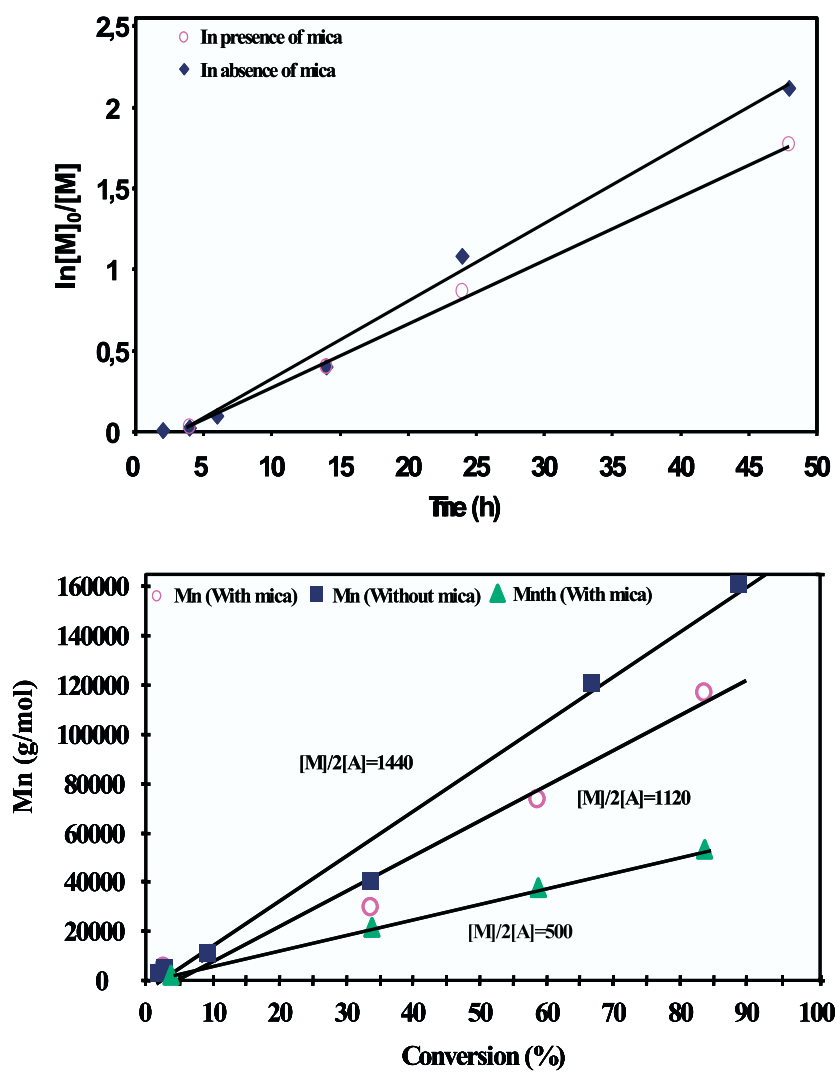

Fig. 5. Variation of (a) $\ln \left([M]_{0} /[M]\right)$ versus time and (b) evolution of $M_{\mathrm{n}}$ as a function of conversion in $\mathrm{SG}_{1}$-mediated polymerisation of $n$-butyl acrylate at $120^{\circ} \mathrm{C}$.
This lends support to the notion that ionic groups are responsible for the binding of polymer chains to the surface.

Moreover, in spite of strictly identical conditions (temperature, concentration as an initiator, excess in SG1), it also noted a slight difference between the two kinetics (in presence and absence of the mica).

In Fig. 5a the plot of the kinetic of polymerisation of butyl acrylate in presence of initiator-adsorbed mica is slower than in absence of mica. This behaviour corresponds to a higher consumption of the BA monomer of the bulk in presence of mica. The mica is well-known as a basic filler due to the $\mathrm{Si}-\mathrm{O}^{-}$on the surface. Knowing that for NMP, the kinetic is increase when $\mathrm{pH}$ decrease, the presence of mica could reduce the polymerisation constant $\mathrm{kp} \mathrm{[24].} \mathrm{This}$ hypothesis have to be confirmed by a more complete study with different mica and initiator ratio.

In the same time Fig. 5b shows an influence of mica to the molecular weight of PBA synthesised. Indeed, in this case the molecular weight is lower in presence of initiatoradsorbed mica. Such a phenomenon is interpreted in terms of an increase of the efficiency of the azoic initiator. From the Fig. 5b, the efficiency of this initiation can be estimated. Indeed, the slope of the straight line is directly correlated to the experimental ratio $[\mathrm{M}] /[\mathrm{A}]$. In this case, the experimental value are around 1120 and 1440, corresponding to a efficiency of 45 and $35 \%$ of the AIBA initiator respectively in presence and in absence of mica. This low value of the efficiency is confirmed by the thermal analysis of the AIBAadsorbed mica, which describes the presence of residual initiator or fragments of the initiators (Section 3.4.3).

Nevertheless, this kinetic study shows a control of polymerisation in presence and absence of mica. Also these result demonstrate that the initiator-adsorbed mica can be used successfully for surface initiated polymerisation of BA from mica surface.

\subsubsection{Characterisation of the free chains by nuclear magnetic resonance (NMR)}

After CES characterisation the unbound polymer $(\mathrm{P}(n-$ BA)) to mica was thoroughly characterized by a ${ }^{1} \mathrm{H}$ NMR $\left(\mathrm{CDCl}_{3}\right)$ sample after $4 \mathrm{~h}$ of reaction (Fig. 6). The spectrum was obtained with clear peaks, such as the typical triple peak at $0.94 \mathrm{ppm}$ and the peak at $4.04 \mathrm{ppm}$, corresponding to the terminal methyl protons $\left(-\mathrm{O}\left(\mathrm{CH}_{2}\right)_{3} \mathrm{CH}_{3}\right)$ and the methylene protons adjacent to oxygen $\left(-\mathrm{OCH}_{2}\left(\mathrm{CH}_{2}\right)_{2} \mathrm{CH}_{3}\right)$ in the 


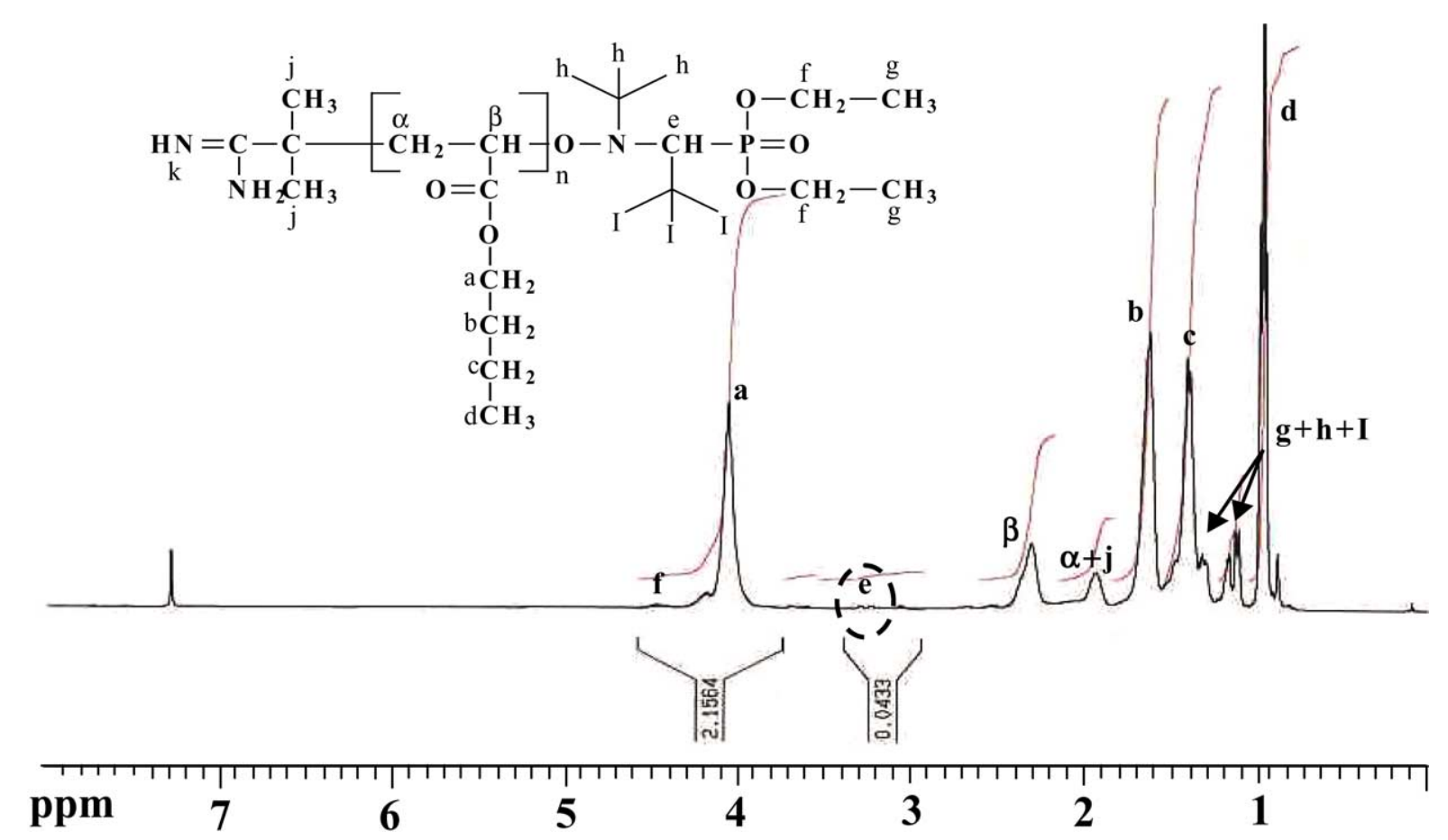

Fig. 6. ${ }^{1} \mathrm{H}$ NMR spectra of PBuA-DEPN (4 h).

$n$-butyl group, respectively. The proton from the other two methylene groups in the $n$-butyl group can also be seen at $1.35 \mathrm{ppm}\left(-\mathrm{OCH}_{2} \mathrm{CH}_{2} \mathrm{CH}_{2} \mathrm{CH}_{3}\right)$ and $1.60 \mathrm{ppm}$ $\left(-\mathrm{OCH}_{2} \mathrm{CH}_{2} \mathrm{CH}_{2} \mathrm{CH}_{3}\right)$.

Concerning the chain end functions, the peaks characteristic of the methyl group of the initiator is not visible in Fig. 7, but hidden by the peaks located between 1.8 and $2 \mathrm{ppm}$ characteristic of proton $\mathrm{H}_{\alpha}$. Also, the spectrum shows the peak characteristic of the $\mathrm{H}_{\mathrm{e}}$ of $\mathrm{SG} 1$ at $3.2 \mathrm{ppm}$ confirming the presence of nitroxide at the end of the chain and giving us the possibility to form block copolymers or to re-initiate a polymerisation.

\subsubsection{Calculation of molecular weight from the ${ }^{1} H$ NMR} spectrum. The NMR spectrum of polymer with lower molecular weight shows peaks characteristic of the counter radical SG1 at the end of polymer chains. Among these peaks, the doublet at $3.2 \mathrm{ppm}$ is assigned to the hydrogen ' $\mathrm{e}$ ' compared to the nitrogen atom of SG1. Neglecting the presence of inactive chains permitted us to estimate the molecular weight of polymer from:

$\left.M_{\mathrm{n}}(\mathrm{RMN})=\left(M \times\left(I_{\mathrm{mu}} / n_{\mathrm{h}}\right)\right) / I_{\mathrm{SG} 1}\right)$

Where: $M$ : molecular weight of monomer $(\mathrm{g} / \mathrm{mol}) ; I_{\mathrm{mu}}$ : integration value of first peak (monomer unit); $I_{\mathrm{SG} 1}$ : integration value of hydrogen e; $n_{\mathrm{h}}$ : hydrogen number of first peak.

The result for sample ( $t=4 \mathrm{~h}$ ) is $M_{\mathrm{n}}=3600 \mathrm{~g} / \mathrm{mol}$, which is in acceptable agreement with the value obtained from GPC $\left(M_{\mathrm{n}}=5000 \mathrm{~g} / \mathrm{mol}\right)$. The difference between the two values may be attributed to the GPC calibration, since the
$M_{\mathrm{n}}$ calculated from chromatogram is given in polystyrene equivalent.

\subsection{Characterisation of hybrid inorganic/organic material}

\subsubsection{FTIR analysis}

At first the polymer-mica composites were characterised qualitatively. A typical FTIR spectrum of the mica-polymer system (4 h) (Fig. 2d), compared to the spectrum of soft mica ${ }^{\circledR}$ (Fig. 2a) and the spectrum of pure AIBA (Fig. 2b), shows the presence of $\mathrm{P}(n-\mathrm{BA})$ on the surface of mica, characteristic of $\mathrm{CH}$ vibrations $\left(2800-3000 \mathrm{~cm}^{-1}\right)$ and $\mathrm{C}=\mathrm{O}$ vibration $\left(1735 \mathrm{~cm}^{-1}\right)$. Also, the spectrum shows the appearance of the $\mathrm{C}=\mathrm{N}$ band $\left(1680 \mathrm{~cm}^{-1}\right)$ and $\mathrm{NH}$ band $\left(1625 \mathrm{~cm}^{-1}\right)$ characteristic of the unreacted initiator. After $4 \mathrm{~h}$ at $120^{\circ} \mathrm{C}$, the AIBA initiator or fragment issue of the initial structure are still present at the surface of mica.

An IR spectrum of the mica-polymer system $(48 \mathrm{~h})$ is shown in Fig. 3e. This last spectrum shows the absence of peaks characteristic of the initiator and the high quantities and the increase in the intensities of the peaks characteristics of $\mathrm{P}(n$-BA), implying a larger quantity of polymer on the surface of the mica. In addition no signals of the azoïc compound or its decomposition products can be seen.

\subsubsection{Interface inorganic/organic: XPS analysis}

XPS measurements were made to characterise modifications to the mica surface.

Fig. 7 summarise the results of the XPS measurements. The spectra of mica shows signals due to the presence of silicate $(152 \mathrm{eV}, \mathrm{Si}(2 \mathrm{~s}) ; 102 \mathrm{eV}, \mathrm{Si}(2 \mathrm{p}))$, aluminate 

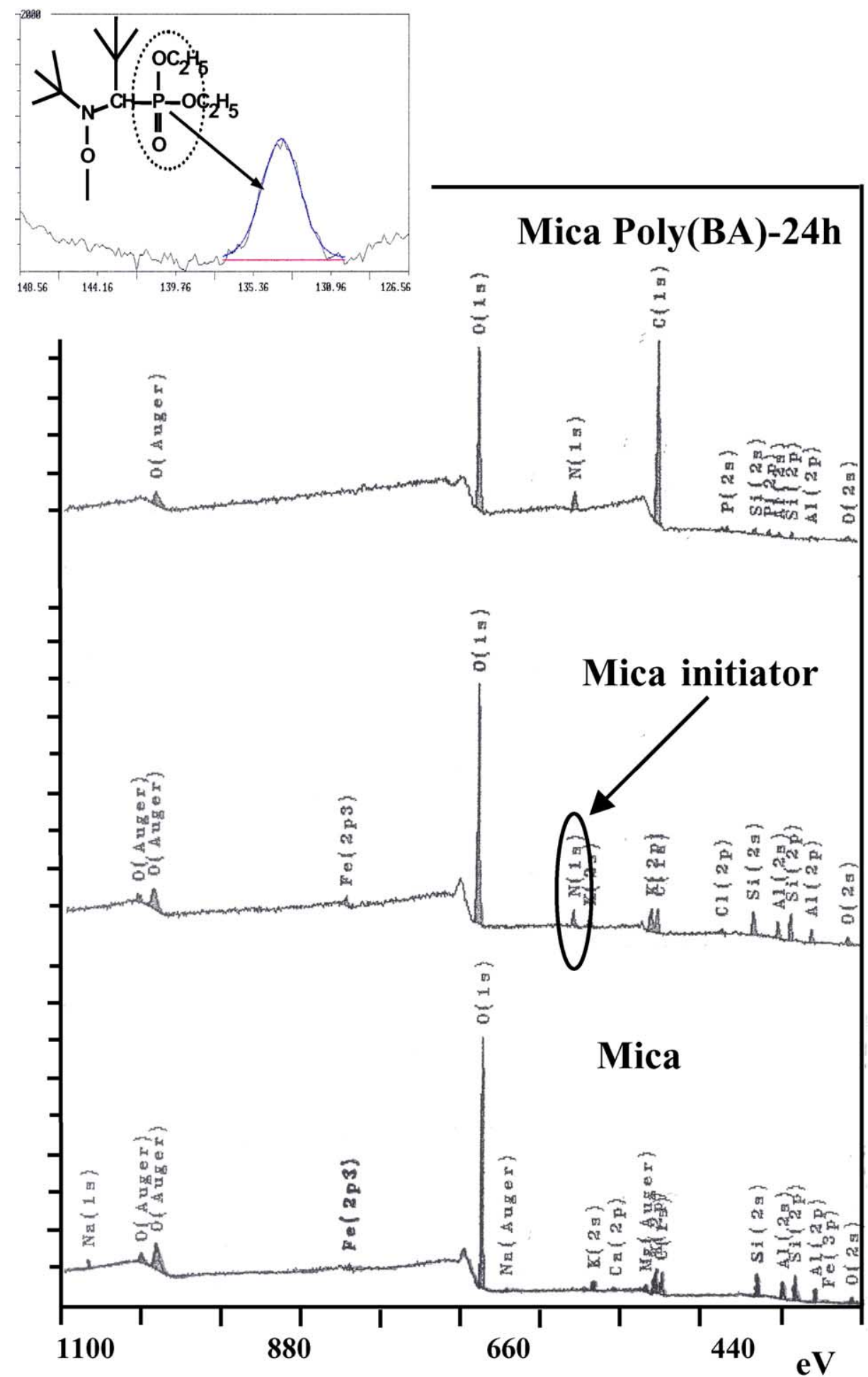

Fig. 7. XPS spectra of poly $\left(n\right.$-BA) $(24 \mathrm{~h})$ coated-mica, AIBA adsorbed-mica and soft mica (insert: $\mathrm{P}(2 \mathrm{p})$ signal of nitroxide $\mathrm{SG}_{1}$ end-capped $\mathrm{PBA}_{\text {. }}$

(110 eV, $\mathrm{Al}(2 \mathrm{~s}) ; 74 \mathrm{eV}, \mathrm{Al}(2 \mathrm{p}))$ and oxygen atoms $(531 \mathrm{eV}$, $\mathrm{O}(1 \mathrm{~s}))$.

After adsorption of AIBA, two new signals appear due to the carbon $(285 \mathrm{eV}, \mathrm{C}(1 \mathrm{~s}))$ and nitrogen atoms $(399 \mathrm{eV}$, $\mathrm{N}(1 \mathrm{~s}))$ of the azo compound and few signals disappeared characteristics of the exchange of mica cations.
A comparison of the XP spectra of the initiator monolayer (d) and the adsorbed $\mathrm{P}(n$-BA) $(4 \mathrm{~h})(\mathrm{c})$ shows a strong enhancement of the carbon signal at $285 \mathrm{eV}(\mathrm{C}(1 \mathrm{~s}))$, and oxygen atoms at $531 \mathrm{eV}(\mathrm{O}(1 \mathrm{~s}))$.

In addition, in the spectrum of Fig. 7, after a longer reaction time $(24 \mathrm{~h})$, the signals of $\mathrm{Si}$ are attenuated and the 


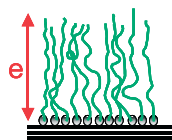

$4 \mathrm{H}$

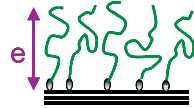

$14 \mathrm{H}$

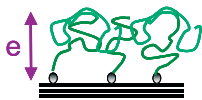

$24 \mathrm{H}$

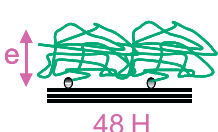

$48 \mathrm{H}$
Scheme 5. Evolution of adsorbed polymer density.

$\mathrm{C}(1 \mathrm{~s}) / \mathrm{O}(1 \mathrm{~s})$ signal ratio is clearly enhanced due to the increase of the molecular weight of the adsorbed polymer chains on mica under controlled conditions. For $48 \mathrm{~h}$ of reaction, the signals of $\mathrm{Si}$ are more attenuated and the $\mathrm{C}(1 \mathrm{~s})$ and to $\mathrm{O}(1 \mathrm{~s})$ signal ratio is more slowly enhanced. Indeed, for this time of polymerisation, the adsorbed polymer density decreases and the controlled character of the growth is lost $\left(M_{\mathrm{w}} / M_{\mathrm{n}}=2.1\right)$, as described previously. Moreover, it must be noted that the signals of $\mathrm{Si}$ and $\mathrm{Al}$ are not totally attenuated due to the decrease of the adsorbed polymer density. These polymers are probably 'crushed' onto the surface of the mica involving a low thickness of the organic layer $(<5-10 \mathrm{~nm})$ due to the conformation of the macromolecular chains in a 'mushroom' mode, (Scheme 5).

However, the XP spectra bring some additional answers due to the presence of peaks associated with the phosphorus atoms $(P(2 \mathrm{p}) ; 133.4 \mathrm{eV})$ characteristic of counter-radical SG1 and more precisely of the group of the type $\mathrm{P}-\mathrm{O}_{n}$, (Insert Fig. 7).

The presence of the large peak at $133.4 \mathrm{eV}$ on the spectrum of mica modified by polymer confirms the presence of nitroxide at the end of the chains. This consequently produces reactivation in order to form copolymers.

\subsubsection{Density of adsorption of macromolecular chains a mica surface}

In order to obtain quantitative information about the graft densities of the ionically adsorbed polymer layers, the materials were examined by TGA. Fig. 3 shows the thermogramme of the mica- $\mathrm{P}(n-\mathrm{BA})$ samples drawn after different times of polymerisation at $120{ }^{\circ} \mathrm{C}$.

For $4 \mathrm{~h}$ of reaction time, three major weight loss 'peaks' were observed: at $180{ }^{\circ} \mathrm{C}$, at $280^{\circ} \mathrm{C}$ and at $377^{\circ} \mathrm{C}$, (see Fig. $3 \mathrm{c})$. Upon comparison of the TGA plots with that of AIBA adsorbed to mica, it was concluded that the observed weight loss at $377^{\circ} \mathrm{C}$ was attributable to the decomposition of $\mathrm{P}(n$ BA) bound to the mica and those around 180 and $280{ }^{\circ} \mathrm{C}$ to AIBA residues, confirming the assumption of the FTIR results of the presence of residual initiator. The maximum of bound polymer obtained was about $0.08 \mathrm{mg}$ per $1 \mathrm{mg}$ of mica, $\left(1.4 \times 10^{-2} \mu \mathrm{mol} / \mathrm{mg}\right.$ of mica $)$.

For $14 \mathrm{~h}$, the maximum of bound polymer obtained was about $0.18 \mathrm{mg}$ per $1 \mathrm{mg}$ of mica $\left(6 \times 10^{-3} \mu \mathrm{mol} / \mathrm{mg}\right.$ of mica). The remainder of the mass loss is attributed to residual AIBA, (see Fig. 3d).

For 24 and $48 \mathrm{~h}$ of reaction, the maximum of bound polymer obtained is significantly higher than is the two precursors, it was respectively $0.33 \mathrm{mg}$ per $1 \mathrm{mg}$ of mica $\left(4.5 \times 10^{-3} \mu \mathrm{mol} / \mathrm{mg}\right.$ of mica) and $0.40 \mathrm{mg}$ per $1 \mathrm{mg}$ of mica $\left(3.4 \times 10^{-3} \mu \mathrm{mol} / \mathrm{g}\right.$ of mica). For $48 \mathrm{~h}$ one major weight loss peak was observed, characteristic of polymer and significant the absence of AIBA residual, (see Fig. 3e and $\mathrm{f}$ ).

From these results it may be noted that the adsorption density of the polymer chains decreases with increasing reaction time, Fig. 8.

The values obtained suggest that the macromolecular chains are 'crushed' more and more onto the mica surface, gradually decreasing the thickness of the organic layer and confirming the results of XPS. Moreover, this phenomenon is related to desorption of the macromolecule chains on a continuous expellation with time probably due to an increase of the affinity of the polymer chains with the bulk. Indeed, when the polymer chains grow from the mica surface, the intermolecular interactions with the free macromolecular chains have to be higher than the ionic interactions between the end chains and the mica surface. Some experiments are underway to understand such a behaviour.

\subsection{Optical properties: $X R D$}

The principal objective of this work is to graft polymer layers onto the surface of mica while preserving its lamellar structure. To check if the layers of this structure were

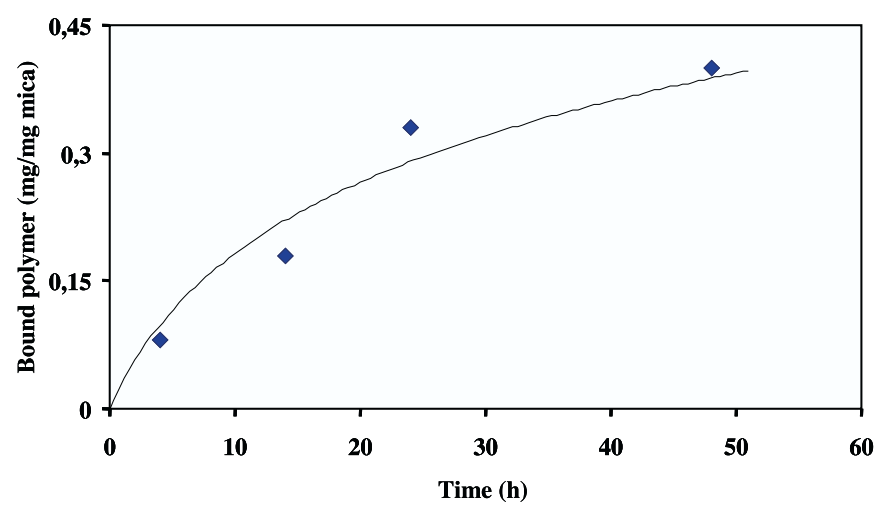

Fig. 8. Bound polymer versus polymerisation time. 


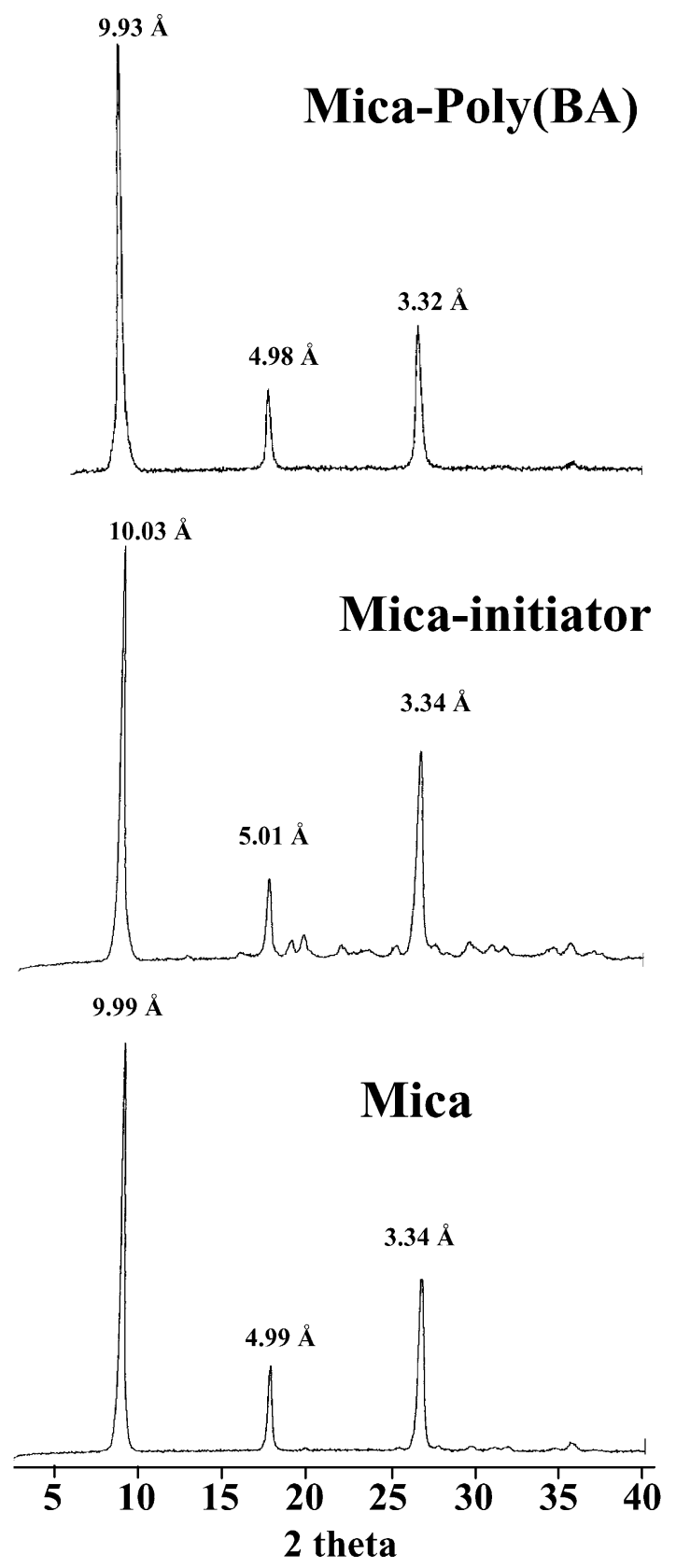

Fig. 9. XRD pattern of poly ( $n$-BA) coated-mica, AIBA adsorbed-mica and (e) soft mica.

damaged during this work, an analysis by X-ray diffraction (XRD) was realised.

The XRD patterns of the resulting solid prepared by adsorption of AIBA at the mica surface, and by grafting of $\mathrm{P}(n$-BA) onto mica for 4,24 and $48 \mathrm{~h}$ are compared to that of soft mica ${ }^{\circledR}$ in Fig. 9.

A strong peak can be observed at $d=9.99 \AA$ in Fig. 9 , which can be assigned to the (001) reflection of mica. Small peaks observed around $d=4.99$ and $3.34 \AA$ are assigned to (002) and (003) reflections. These values are in agreement with those of the work of Bentayeb et al. [25], which gives inter-reticular distances for the most intense peaks at 10.10, 5.10 and $3.32 \AA$ for a mica phase.
The other XRD patterns of Fig. 9 also reveal the presence of reflections of the plans of the mica phase. The treatments carried out on the compound relative mica do not seem to have affected its lamellar structure.

\section{Conclusion}

In this study we developed a novel way to connects through ionic bounds the $\mathrm{P}(n-\mathrm{BA})$ to layered silicate for the first time by nitroxide mediated polymerisation.

The polymerisation of butyl acrylate with initiator adsorbed onto mica, under quite precise conditions, leads to an adsorbed quantity of polymer of about $0.08 \mathrm{mg} / \mathrm{mg}$ of mica, after $4 \mathrm{~h}$ of reaction. This is very low and unsatisfactory, compared to the significant quantity of residual initiator. By increasing the time of polymerisation, the adsorbed polymer quantity obtained is $0.33 \mathrm{mg}$ per $1 \mathrm{mg}$ of mica for $24 \mathrm{~h}$ (molecular weight of $74,000 \mathrm{~g} / \mathrm{mol}$ and polydispersity of 1.17) under a controlled free radical reaction.

The kinetic study both in presence and absence of mica shows a control of the surface initiated nitroxide mediated polymerisation, by the linear variation of $\ln [M]_{0} /[M]$ versus time and also linear variation of molecular weight versus conversion. This study demonstrates also that the presence of mica in the bulk reduces the kinetic of polymerisation and the molecular weights. This behaviour can be associated to a low efficiency of the initiator and to the basicity of the mica filler. On the other hand, the presence of the mineral does not have an influence on the index of polydispersity.

The characterisation of grafted material obtained by several techniques (FTIR, X-ray diffraction, XPS, etc.) shows that it is in conformity with our objective, i.e. that one preserves the lamellar structure of the mica while adsorbing a layer of polymer.

Quantitative and qualitative results demonstrate that using a surface bound AIBA initiator, it is possible to obtain a $\mathrm{P}(n-\mathrm{BA})$ monolayer bound to mica. The next step will consist of a synthesis of block copolymers from a $\mathrm{P}(n-\mathrm{BA})$ adsorbed to mica and will be presented in a forthcoming paper.

\section{Acknowledgements}

We would like to thank A. Khoukh for NMR measurements, J.C. Dupin for XRD and C. Guimon for XPS measurements. We are also pleased to acknowledge DUPONT for supplying AIBA and ATOFINA for supplying SG1. A special thank to P. Maury from 2PSM 'Propriétés Psychosensorielles des Matériaux' for his support and motivation. 


\section{References}

[1] Caseri WR, Suter UW. In: Salamone JC, editor. The polymeric materials encyclopedia, vol. 5. Boca Raton, FL: CRC Press; 1996

[2] Debnath S, De Prajna P, Khastgir D. Rubber Chem Technol 1988;61: 555.

[3] Xavier SF, Sharma YN. Polym Compos 1986;7:42.

[4] Sodergard A, Ekman K, Stenlund B, Lassas A-C. Appl Polym Sci 1996;59:1709.

[5] Georges MK, Veregin RN, Kazmaier PM, Hamer GK. Macromolecules 1993;26:2987.

[6] Mardare D, Matyjaszewski K. Polym Prep ACS Polym Div 1994; 35(1):557.

[7] Wang JS, Matyjaszewski K. Macromolecules 1995;28:7901.

[8] Granel C, Dubois Ph, Jérome R, Teyssié Ph. Macromolecules 1996; 29:8576.

[9] Matyjaszewski K. ACS Symp Ser 1998;685:258.

[10] Chiefari J, Chong YK, Ercole F, Kristina J, Jeffery J, Le TPT, Mayadunne RTA, Meijs GF, Moad CL, Rizzardo E, Thang SH. Macromolecules 1998;31:5559.

[11] Chong YK, Le TPT, Moad G, Rizzardo E, Thang SH. Macromolecules 1999;32:2071.

[12] Grimaldi S, Finet JP, Zeghdaoui A, Tordo P, Benoit D, Gnanou Y, Fontanille M, Nicol P, Pierson JF. Polym Prep 1997;38(1):651.
[13] Robin S, Gnanou Y. Polym Prep 1999;40(2):387.

[14] Parvole J, Billon L, Montfort JP. Polym Int 2002;51:1111.

[15] Parvole J, Laruelle G, Guimon C, François J, Billon L. Macromol Rapid Commun 2003;24:1074.

[16] Bartholome C, Beyou E, Bourgeat-Lami E, Chaumont P, Zidowicz N. Macromolecules 2003;36:7946.

[17] Husseman M, Malmström EE, McNamara M, Mate M, Mecerreyes D, Benoît D, Hedrick JL, Mansky P, Huang E, Russel TP, Hawker CJ. Macromolecules 1999;32:1424.

[18] Kasseh A, Ait-Kadi A, Riedl B, Pierson JF. Polymer 2003;44:1367.

[19] Bailey SW. Reviews in mineralogy, vol. 13. Blacksburg: Virginia Polytechnic Institute and State University; 1994 p. 1.

[20] Meier LP, Shelden RA, Caseri WR, Suter UW. Macromolecules 1994; 27:1637.

[21] Benoit D, Grimaldi S, Finet JP, Tordo P, Fontanille M, Gnanou Y. ACS Symp Ser 1998;685:255.

[22] Velten U, Shelden RA, Caseri WR, Suter UW, Li Y. Colloid Surf A 1999; $154: 87$.

[23] Parvole J, Montfort JP, Billon L. Macromol Chem Phys 2004;205: 1369.

[24] Malmeström E, Miller RD, Hawker CJ. Tetrahedron 1997;45:15225.

[25] Bentayeb A, Amouric JO, Dekayir A, Nadiri A. Appl Clay Sci 2003; $22: 211$. 